Unlike the ascending aorta and aortic arch, there was no association between the descending aorta and $A P O E^{*} E 4$. Potential reasons for this include the fact that the progression of atherosclerosis in the aorta is influenced by the flow dynamics and wall shear stress within the segments of the aorta. ${ }^{4}$ For example, the higher ejection velocity in the ascending aorta might limit formation of plaques in this region. More importantly, the influence of age on atherosclerosis is very strong, with an incidence rising steadily with age. ${ }^{5}$ Because patients undergoing cardiac surgery are increasingly elderly, the effect of $A P O E^{*} E 4$ might be masked by the dominating influence of age on atherosclerosis, particularly in the descending aorta.

Limitations to our study include the fact that our technique uses a 2-dimensional, rather than 3-dimensional, image of a specific aortic segment. Nevertheless, the percentage of atheroma method that we used does at least account for total plaque area that can be visualized. Finally, epiaortic imaging is a more sensitive measure of assessing plaque in the ascending aorta, and it is possible that a greater degree of atherosclerosis might have been detected, with its use potentially improving the link between atheroma burden and the $A P O E^{*} E 4$ allele.

\section{References}

1. Tardiff BE, Newman MF, Saunders AM, et al. Preliminary report of a genetic basis for cognitive decline after cardiac operations. The Neurologic Outcome Research Group of the Duke Heart Center. Ann Thorac Surg. 1997;64:715-20.

2. Saunders AM, Strittmatter WJ, Schmechel D, et al. Association of apolipoprotein E allele epsilon 4 with late-onset familial and sporadic Alzheimer's disease. Neurology. 1993;43:1467-72.

3. Hogue CW Jr, Murphy SF, Schechtman KB, Davila-Roman VG. Risk factors for early or delayed stroke after cardiac surgery. Circulation. 1999; 100:642-7.

4. Stanton AV. Haemodynamics, wall mechanics and atheroma: a clinician's perspective. Proc Inst Mech Eng [H]. 1999;213:385-90.

5. Marschall K, Kanchuger M, Kessler K, et al. Superiority of transesophageal echocardiography in detecting aortic arch atheromatous disease: identification of patients at increased risk of stroke during cardiac surgery. J Cardiothorac Vasc Anesth. 1994;8:5-13.

\title{
Systemic allergic reaction to the percutaneous patent foramen ovale occluder
}

\author{
Kazuaki Fukahara, MD, ${ }^{a}$ Kazutomo Minami, MD, ${ }^{a}$ Nils Reiss, MD, ${ }^{a}$ Dieter Fassbender, MD, ${ }^{\mathrm{b}}$ and \\ Reiner Koerfer, MD, ${ }^{a}$ Bad Oeynhausen, Germany
}

$\mathrm{T}$ ranscatheter occlusion of an atrial septal defect or patent foramen ovale (PFO) has become an effective and less invasive alternative to cardiac surgery. ${ }^{1}$ A number of complications have been recognized. ${ }^{2}$ However, hypersensitivity or allergic reaction to the device itself has been not reported.

We treated a patient who had a systemic allergic reaction to the percutaneous PFO occluder. The case is described, and the therapeutic implication is discussed.

\section{Clinical Summary}

A 37-year-old woman with a PFO was admitted to our institution for transcatheter occlusion of her PFO. She had an episode of

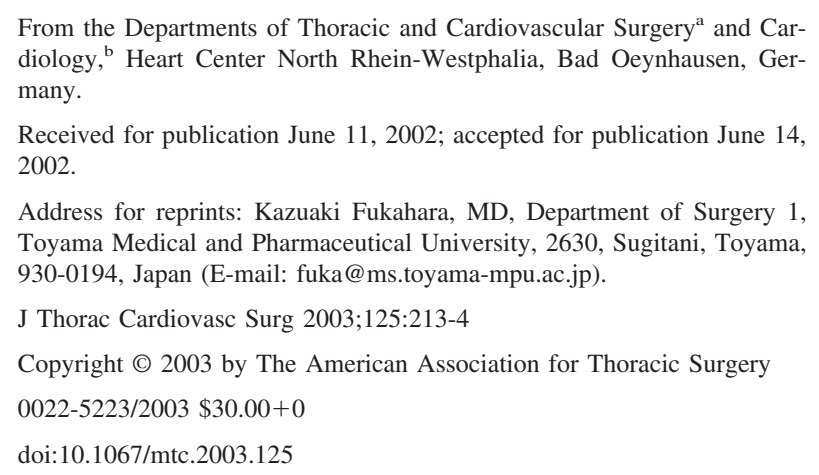

paradoxical cerebral embolism 1 year previously, and anticoagulation therapy with phenprocoumon had been initiated. Despite anticoagulation therapy, the patient had a transient ischemic attack 6 months before admission. She was offered the option of transcatheter occlusion of her PFO, and she agreed to the procedure. The patient had slight exertional dyspnea (New York Heart Association class I-II) but had no body weight change or fever at the time of admission.

Transvenous occlusion of the PFO was performed with a PFOStar device (Cardia Inc, Burnsville, Minn) by using a $30-\mathrm{mm}$ umbrella under transesophageal echocardiographic guidance. The postinterventional studies showed that the position of the device was satisfactory, and there was no residual shunt.

Two months after PFO occlusion, the patient began having dyspnea, a temperature of $38^{\circ} \mathrm{C}$, and dependent edema. Endocarditis or infection of the device was suspected, and she was referred back to our institution. Laboratory examination revealed a white blood cell count of $8800 \mathrm{mg} / \mathrm{dL}$ (granulocytes, 51.9\%; lymphocytes, $31.4 \%$; monocytes, $9.8 \%$; eosinophils, $5.7 \%$; and basophils, $1.2 \%$ ), a hemoglobin concentration of $14.5 \mathrm{~g} / \mathrm{dL}$, a hematocrit level of $43.2 \%$, a platelet count of $256,000 / \mathrm{dL}$, and a C-reactive protein concentration of $0.8 \mathrm{mg} / \mathrm{dL}$; other biochemical indices were within normal limits. Echocardiography with color Doppler scanning showed no residual shunt, no findings suggestive of intracardiac vegetation, and good cardiac function. Blood cultures were performed several times, but each showed no growth. Her history was significant for allergic reactions to some medications 


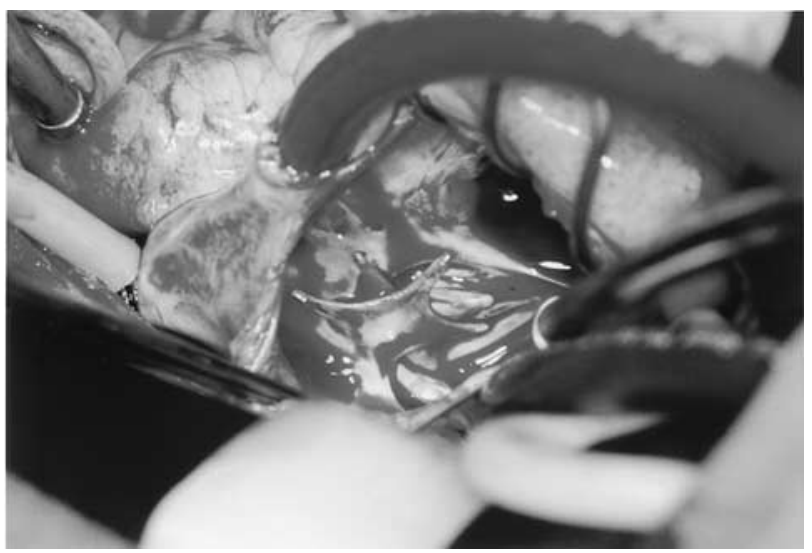

Figure 1. Intraoperative view of the percutaneous PFO occluder.

and an episode of allergic asthma. With high levels of immunoglobulin E (144 U/mL; normal range, 0-100 U/mL) and eosinophilic cations protein $(29 \mu \mathrm{g} / \mathrm{mL}$; normal rangem 2.3-12.0 $\mu \mathrm{g} /$ $\mathrm{mL}$ ), we assumed the patient was having a hypersensitivity reaction to the PFO occluder. Skin patch testing was performed with nitinol, the primary component of the device, and results were positive in both the early and late phases.

Because the high-grade fever and edema persisted, the patient agreed to explantation of the device. Four months after transcatheter PFO occlusion, the device was removed surgically, and PFO closure with an autologous pericardial patch was performed during extracoreporeal cardiopulmonary bypass. Intraoperative examination showed that the device appeared to be functioning properly (Figure 1). Pathologic examination of the device showed nonspecific inflammation with no evidence of infection. The patient recovered uneventfully and is doing well 1 year postoperatively.

\section{Discussion}

A PFO might result in recurrent paradoxical embolism, leading to stroke or occlusion of the peripheral artery. ${ }^{1}$ Recently, transcatheter closure has been offered to these patients as an effective and less invasive therapeutic option. However, these procedures are not free of potential problems. Reported complications include cerebral embolism, cardiac perforation, malpositioning of the device with residual shunt, vascular trauma, thrombus formation on the device, and interference with atrioventricular valve function. ${ }^{2}$ This is the first report of hypersensitivity to the device itself.
Nitinol is a shape-memory alloy with good biocompatibility. Nitinol is composed of nickel (55\%) and titanium (45\%) and is suitable for the fabrication of endovascular and intracardiac devices. Recently, it has been used more widely for other types of interventional procedures as well. ${ }^{3}$ On the other hand, it is widely known that nickel is highly allergenic. Recently Köster and colleagues ${ }^{4}$ reported a higher frequency of coronary in-stent restenosis in patients with delayed-type hypersensitivity to nickel than in patients without sensitization to nickel. They recommended that all patients who are candidates for coronary stent implantation should be asked specifically about previous or present metal allergies.

In our patient the clinical course and positive skin patch test result led to the presumptive diagnosis of hypersensitivity to the device. However, pathologic examination showed only nonspecific inflammation, without infiltration by eosinophils. Thus, we cannot say unequivocally that the patient had an allergic reaction to the device. The positive result of the skin patch test is not adequate to establish hypersensitivity. However, in conjunction with the clinical course (ie, the persistent symptoms that resolved with removal of the device), a hypersensitivity reaction is the most likely diagnosis.

Systemic allergic reaction to the PFO occluder might not be common, but the potential risk of nickel toxicity should not be ignored. ${ }^{5}$ The value of preoperative skin patch testing for metals in all patients is controversial, but testing is likely justified in patients with a history of allergic reactions. Regardless of results, however, the risks and benefits of therapeutic options with metal-containing intracardial or endovascular devices in such patients must be considered carefully.

\section{References}

1. Windecker S, Wahl A, Chatterjee T, Garachemani A, Eberli FR, Seiler $\mathrm{C}$, et al. Percutaneous closure of patent foramen ovale in patients with paradoxical embolism: long-term risk of recurrent thromboembolic events. Circulation. 2000;101:893-98.

2. Rigby ML. The era of transcatheter closure of atrial septal defects. Heart. 1999;81:227-28.

3. Hill AC, Maroney TP, Virmani R. Facilitated coronary anastomosis using a nitinol U-Clip device: bovine model. $J$ Thorac Cardiovasc Surg. 2001;121:859-70.

4. Köster R, Vieluf D, Kiehn M, Sommerauer M, Kähler J, Baldus S, et al. Nickel and molybdenum contact allergies in patients with coronary in-stent restenosis. Lancet. 2000;356:1895-7.

5. Lhotka CG, Szekeres T, Fritzer-Szekeres M, Schwarz G, Steffan I, Maschke M, et al. Are allergic reactions to skin clips associated with delayed wound healing? Am J Surg. 1998;176:320-3. 